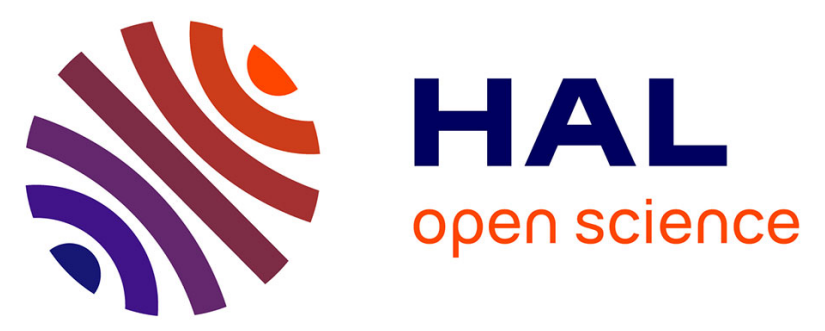

\title{
Removal of Chromium and Aluminum from Aqueous Solutions Using Refuse Derived Char
}

Catarina Nobre, Margarida Gonçalves, Dieimes Resende, Cândida Vilarinho, Benilde Mendes

\section{- To cite this version:}

Catarina Nobre, Margarida Gonçalves, Dieimes Resende, Cândida Vilarinho, Benilde Mendes. Removal of Chromium and Aluminum from Aqueous Solutions Using Refuse Derived Char. 7th Doctoral Conference on Computing, Electrical and Industrial Systems (DoCEIS), Apr 2016, Costa de Caparica, Portugal. pp.515-522, 10.1007/978-3-319-31165-4_48 . hal-01438278

\section{HAL Id: hal-01438278 \\ https://inria.hal.science/hal-01438278}

Submitted on 17 Jan 2017

HAL is a multi-disciplinary open access archive for the deposit and dissemination of scientific research documents, whether they are published or not. The documents may come from teaching and research institutions in France or abroad, or from public or private research centers.
L'archive ouverte pluridisciplinaire HAL, est destinée au dépôt et à la diffusion de documents scientifiques de niveau recherche, publiés ou non, émanant des établissements d'enseignement et de recherche français ou étrangers, des laboratoires publics ou privés. 


\title{
Removal of Chromium and Aluminum from Aqueous Solutions Using Refuse Derived Char
}

\author{
Catarina Nobre', Margarida Gonçalves' ${ }^{1}$, Dieimes Resende², Cândida Vilarinho \\ Benilde Mendes ${ }^{1}$ \\ ${ }^{1}$ MEtRICs, Departamento de Ciências e Tecnologia da Biomassa, Faculdade de Ciências e \\ Tecnologia, Universidade Nova de Lisboa, 2829-516 Caparica \\ ${ }^{2}$ Departamento de Ciências Florestais, Universidade Federal de Lavras, Av. Doutor Sylvio \\ Menicucci, 1001-Kennedy, Lavras-MG, 37200-000, Brasil. \\ ${ }^{3}$ MEtRICs, Departamento de Engenharia Mecânica, Escola de Engenharia, \\ Universidade do Minho, 4804-533 Guimarães, Portugal. \\ \{cp.nobre@campus.fct.unl.pt; dieimes.rr@posgrad.ufla.br; mmpg@fct.unl.pt; \\ candida@dem.uminho.pt; bm@fct.unl.pt \}
}

\begin{abstract}
Refuse derived fuel (RDF) was subject to torrefaction in order to produce a char with higher homogeneity and lower moisture content than the RDF raw materials. The resulting product, RDF char, showed increased fixed carbon and ash contents, decreased moisture and volatile matter contents, and a very significant increase in density. The torrefaction of RDF may therefore contribute to reduce the landfill volume needed to accommodate these materials to one third of the presently used. This new char material was also tested for its adsorption capacities and the results show that it could be used for the removal of chromium and aluminum from aqueous solutions.
\end{abstract}

Keywords: RDF, char, adsorption, chromium, aluminum.

\section{Introduction}

Refuse derived fuel (RDF) is an heterogeneous material comprehending polymeric and lignocellulosic waste that cannot be recycled and must be disposed of in landfills or used for energy purposes by co-combustion in cement kilns or power plants [1]. Landfill deposition is a source of environmental problems and it is not advised by current legislation that foresees a reduction of $59 \%$ of the presently eliminated wastes to be achieved by 2020 [2].

On the other hand, the energetic valorization of waste derived fuels faces several constrains namely their high degree of heterogeneity, low density and high moisture, chlorine and ash contents. Moreover, the fuel applications of RDFs are often limited by their high content of polymeric wastes that causes agglomeration problems in the feeding systems of boilers or gasifiers and increases solid and gaseous emissions associated with incomplete combustion or gasification. 
The research question addressed in this $\mathrm{PhD}$ program is the development sustainable solutions for the upgrading and valorization of RDFs either as better quality fuels or as refuse derived materials with industrial applications.

These technological solutions aim to modify the RDFs in order to increase density, homogeneity, hydrophobicity and calorific value by reduction of moisture, volatile matter, microbiological contamination and by rearrangement of the chemical bonds from the non-volatile fraction.

The techniques selected to achieve this goal are thermochemical processes, namely torrefaction, pyrolysis and gasification. These processes apply high temperatures, in the presence of oxidizing agents or inert gases, leading to an extensive reorganization of the molecular structure and contributing to a composition upgrading by eliminating oxygen, chlorine and other heteroatoms.

Torrefaction occurs at $200-300^{\circ} \mathrm{C}$ under an inert atmosphere. It is the first step to obtain a stabilized RDF and has proven to be a useful tool to upgrade solid fuels such as raw biomass [3]. The torrefied RDF can then be directed to various final applications such as land reclamation, production of solid, liquid or gaseous fuels, incorporation into building materials or production of refuse derived materials such as refuse derived chars. The program of activities of this $\mathrm{PhD}$ program comprises the following tasks:

a) Evaluate the influence of torrefaction conditions and initial RDF composition in the final physico-chemical properties of torrefied RDFs;

b) Determine gaseous emissions associated with RDF torrefaction;

c) Evaluate the combustion behavior of torrefied RDFs in what concerns efficiency and associated emissions;

d) Study the conversion of torrefied RDFs in liquid fuels using pyrolysis or hydrothermal liquefaction;

e) Study the conversion of torrefied RDFs in gaseous fuels using thermal gasification;

f) Evaluate the adsorbent characteristics of torrefied RDFs in different industrial applications (dyes, heavy metals and pesticides).

Modern industries use a significant amount of resources in the remediation of contaminated effluents that contain relevant concentrations of organic and inorganic hazardous compounds which are considered environmental priority pollutants [4].

Activated carbons are the most used adsorbents but they have high prices and are difficult to regenerate so they represent a constant investment as raw materials and a constant source of contaminated solid wastes.

In this context there is a growing interest in the production of low-cost adsorbents, derived from less expensive or residual materials such as agricultural wastes, industrial by-products, waste materials or natural substances [5].

In this work, a refused derived char (RDF char) was produced by torrefaction of $\mathrm{RDF}$ at $300{ }^{\circ} \mathrm{C}$ during 30 minutes. The RDF char was characterized for its proximate composition, heating value and density and its adsorption capacity towards chromium and aluminum was tested using different metal concentrations, adsorption times, initial $\mathrm{pH}$ and adsorbent-to-metal mass ratios. 


\section{Relationship to Cyber-Physical Systems}

The torrefaction of RDF is a thermochemical process that requires the heating of the raw RDF at temperatures in the range of $250^{\circ} \mathrm{C}$ to $350{ }^{\circ} \mathrm{C}$ during variable periods of time. The efficiency of the process depends strongly on the characteristics of the raw RDF namely its moisture content that influences the real temperature in the torrefaction unit. For the same amount of energy supplied, the maximum temperature measured in a given period of time is inversely proportional to the moisture content of the raw material. Thus, torrefaction is effective when the moisture and a substantial fraction of the volatile components are eliminated, therefore the automated monitoring of the torrefaction process requires the use of temperature sensors that enable the establishment of real temperature profiles during the process.

On the other hand, the thermal capacity of the raw RDF also influences the kinetics and extension of the torrefaction process, so the flow of gaseous products is also a key parameter to control this process.

The combination of those two variables (temperature and flow of the gaseous emissions) reflects the completion of the torrefaction process and may be used as a boundary condition to regulate the feed, for different RDF compositions.

The remediation of industrial effluents using adsorption processes is a technology that requires the implementation of automatic control and monitoring systems that comprehend sensors for the continuous evaluation of effluent composition and concentrations of critical components (for instance, electrochemical sensors), in association with intelligent systems for the control of mechanical operations such as pressure and flow control as well as diversion of the effluent flow to alternative adsorption columns or stopping the process when the adsorbent becomes saturated.

\section{Methods and Materials}

\subsection{RDF Char Production and Characterization}

Industrial refuse derived fuel was supplied by CITRI, S.A. This raw material was mainly composed of plastics, cigarette buds, rubber, fabric and lignocellulosic material. The torrefaction of RDF was performed in closed lid crucibles placed in a muffle furnace (Nabertherm) for 30 minutes at $300{ }^{\circ} \mathrm{C}$.

Both the RDF and the RDF char were grinded and the char was sieved to a particle diameter of less than $500 \mu \mathrm{m}$ and were characterized for proximate analysis (moisture, volatile matter, ash and fixed carbon contents) and density. All proximate analysis parameters were determined according to ASTM standards for RDF. The high heating values (HHV) were evaluated using an equation that relates this property to the proximate analysis of the materials [6].

\subsection{Adsorption Experiments}

The adsorption of $\mathrm{Cr}$ and $\mathrm{Al}$ was studied using solutions of $\mathrm{AlCl}_{3}$ and $\mathrm{K}_{2} \mathrm{Cr}_{2} \mathrm{O}_{7}$ prepared with ultra-pure water at a concentration of $100 \mathrm{mg} / \mathrm{L}$. These solutions (100 
$\mathrm{mL})$ contacted with the RDF char $(0.2 \mathrm{~g})$, in stopped Schott glass flasks, at room temperature, for $2 \mathrm{~h}$, at a $\mathrm{pH}$ of 8.0 , under agitation $(15 \mathrm{rpm})$ in an overhead shaker (Heidolph). The RDF char and metal solutions were separated by filtration and the concentrations of $\mathrm{Cr}$ and $\mathrm{Al}$ in the filtrate were determined by atomic absorption spectroscopy (Thermo Elemental Solaar). All the measurements were performed in triplicate and the reported values correspond to the average values.

The effect of $\mathrm{pH}$ on the adsorption of chromium and aluminum was studied in a range from 2.0 to 10.0 and the initial $\mathrm{pH}$ value was adjusted to the target values by using $\mathrm{NaOH} 1 \mathrm{M}$ or $\mathrm{HCl} 1 \mathrm{M}$ (Panreac). The influence of the contact time on the metal adsorption by the RDF char was evaluated for contact times from 0 to 600 minutes. The effect of initial metal concentration was determined varying the initial concentrations from 30 to $150 \mathrm{mg} / \mathrm{L}$. The effect of adsorbent mass was tested in a range of 0.1 to $0.8 \mathrm{~g}$, for metal solutions with an initial concentration of $100 \mathrm{mg} / \mathrm{L}$. The adsorption capacity, $\mathrm{q}(\mathrm{mg} / \mathrm{g})$, of the RDF char was determined according to Equation 1:

$$
\mathrm{q}(\mathrm{mg} / \mathrm{g})=\left(\left(\mathrm{C}_{0}-\mathrm{C}_{\mathrm{f}}\right) * \mathrm{~V}\right) / \mathrm{m}
$$

The metal removal efficiency, R (\%), was determined according to Equation 2:

$$
\mathrm{R}(\%)=\left(\left(\mathrm{C}_{0}-\mathrm{C}_{\mathrm{f}}\right) / \mathrm{C}_{0}\right) .100
$$

where $\mathrm{C}_{0}$ and $\mathrm{C}_{\mathrm{f}}$ are the initial and final metal concentrations $(\mathrm{mg} / \mathrm{L})$, respectively, $\mathrm{V}$ is the volume of the solution $(\mathrm{L})$, and $\mathrm{m}$ is the char mass $(\mathrm{g})$.

\section{Results and Discussion}

\subsection{RDF Char Characterization}

The results for the characterization of standard RDF and its corresponding RDF char are presented in Table 1. When compared to the standard RDF, the RDF char shows a very significant increase in the fixed carbon content and density, which has very important implications in handling and storage. The ash content of the RDF char is very high (19.83\%), affecting negatively the estimated high heating value (HHV) and limiting the applications of these chars in energy conversion systems such as boilers, mainly due to their potential for slagging and fouling phenomena. Nevertheless the torrefaction process may be regarded as an advanced treatment to increase the density and reduce the moisture of RDFs, enabling important reductions in landfill land use and reducing the effluent emissions in storage sites. 
Table 1. Fuel characteristics of standard RDF and corresponding RDF char.

\begin{tabular}{lcc}
\hline & Standard RDF & RDF char \\
\hline Proximate analysis & & \\
Moisture $(\% \mathrm{w} / \mathrm{w}, \mathrm{wb})$ & $6.02 \pm 0.34$ & $2.32 \pm 0.18$ \\
Volatile matter $(\% \mathrm{w} / \mathrm{w}, \mathrm{db})$ & $82.58 \pm 1.03$ & $59.69 \pm 1.18$ \\
Ash $(\% \mathrm{w} / \mathrm{w}, \mathrm{db})$ & $8.20 \pm 1.21$ & $19.83 \pm 0.47$ \\
Fixed carbon $(\% \mathrm{w} / \mathrm{w}, \mathrm{db})$ & $9.22 \pm 0.26$ & $20.48 \pm 0.74$ \\
\hline Estimated $\mathrm{HHV}(\mathrm{MJ} / \mathrm{Kg})^{1}$ & 17.68 & 15.70 \\
Density $\left(\mathrm{g} / \mathrm{cm}^{3}\right)$ & $0.12 \pm 0.01$ & $0.46 \pm 0.04$ \\
\hline
\end{tabular}

Another approach regarding the valorization of this material is its use as a low cost adsorbent for industrial applications. Our goal is to eventually use this char to remediate the liquid effluents produced by the same companies that produce the RDF in an integrated perspective of waste management. Following this approach, the heavy metals chromium and aluminum (that are frequently present in these effluents) were chosen as adsorbates for a series of tests concerning the adsorption capacity of the RDF char.

\subsection{Adsorption Experiments}

Effect of pH. It is well documented that $\mathrm{pH}$ affects significantly the adsorption capacity of an adsorbent used for heavy metal removal from aqueous solutions, mostly because it influences the ionic forms of the metals in solution [7]. The effect of the initial $\mathrm{pH}$ of the metal solutions in the removal efficiency by the RDF char is shown in Fig.1.

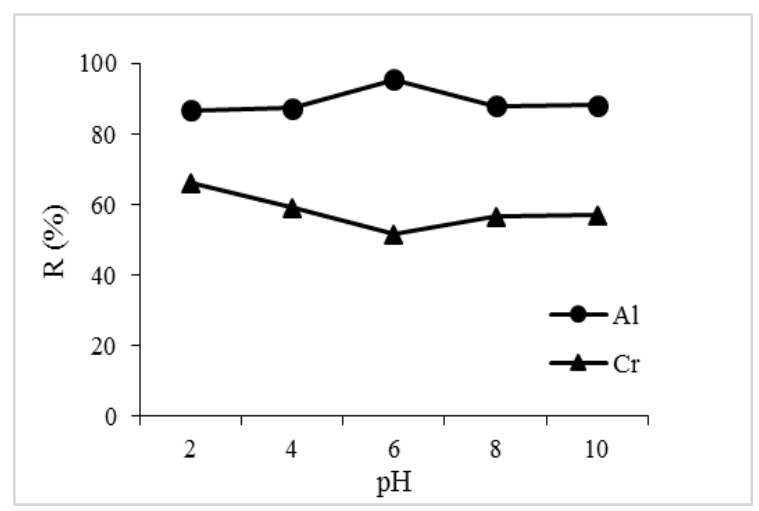

Fig. 1. Effect of solution $\mathrm{pH}$ on the removal efficiency (R) of $\mathrm{Al}$ and $\mathrm{Cr}$.

Aluminum presents its higher removal efficiency value for $\mathrm{pH} 6(95.5 \%)$, which is in accordance with the determinations of other authors using different adsorbents [8]. 
On the other hand, chromium is better adsorbed at more acidic $\mathrm{pH}(\mathrm{pH} 2)$, reaching a removal efficiency of $66.0 \%$. This high removal efficiency of chromium at low $\mathrm{pH}$ can be due to the increase in the protonation of functional groups from the char surface, producing a strong electrostatic interaction between the char and negatively charged oxyanion forms of $\mathrm{Cr}(\mathrm{VI})$ such as $\mathrm{HCrO}_{4}{ }^{-}, \mathrm{Cr}_{2} \mathrm{O}_{7}{ }^{2-}$, and $\mathrm{CrO}_{4}{ }^{2-}$ which are prevalent in the potassium dichromate solutions and may be significant in real effluents [9]. Regardless of the obtained removal efficiencies it was decided to perform the remaining tests at the natural $\mathrm{pH}$ of real landfill leachates samples $(\mathrm{pH}$ 8.0).

Effect of adsorbent mass. The adsorbent mass or adsorbent dose is a significant parameter considering removal efficiency because it is related to the adsorbentadsorbate equilibrium [10]. The results obtained for this parameter are shown in Fig. 2.

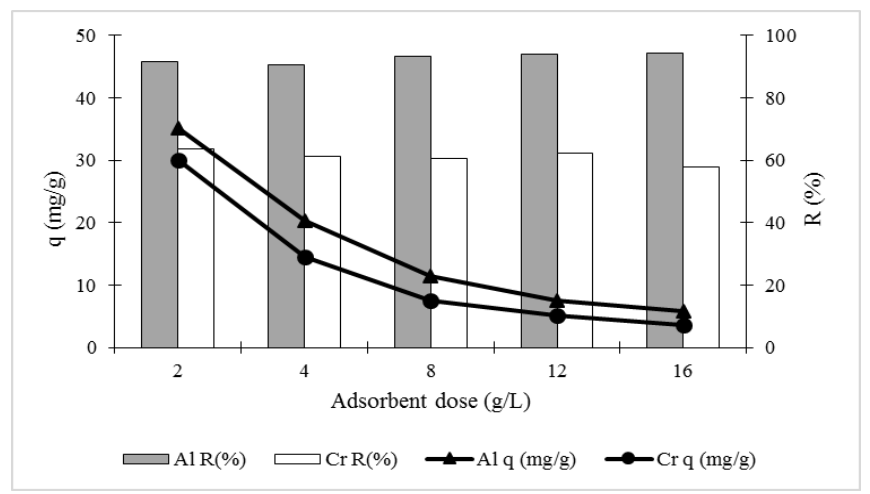

Fig. 2. Effect of adsorbent dose (g/L) on the adsorption capacity (q) and removal efficiency (R) of $\mathrm{Al}$ and $\mathrm{Cr}$.

The removal efficiencies of $\mathrm{Al}$ and $\mathrm{Cr}$ didn't change significantly when the adsorbent dose changed from $2 \mathrm{~g} / \mathrm{L}$ to $16 \mathrm{~g} / \mathrm{L}$, indicating that maximum extraction was achieved at a $2 \mathrm{~g} / \mathrm{L}$ dose. The different ionic forms of the metals will bind to the char surface groups through electrostatic and hydrophobic interactions but as their concentration in solution decreases the concentration gradient favors a certain degree of desorption stabilizing in a concentration ratio that is constant for each metal. The average removal efficiency was of $93 \%$ for $\mathrm{Al}$ while for $\mathrm{Cr}$ was of $61 \%$, what may result from a wider speciation of $\mathrm{Cr}$, yielding a variety of ionic species with different net charges, limiting their removal by adsorption when the electrostatic and hydrophobic interactions are dominant.

On the other hand, the adsorption capacity decreases as the adsorbent dose increases indicating that the equilibrium between char and solution is achieved at 2 $\mathrm{g} / \mathrm{L}$. Increasing the adsorbent mass has a dilution effect in the adsorption capacity since the final concentration of metals in the char was inversely proportional to the adsorbent dose. 
Effect of metal initial concentration. The removal efficiency of the RDF char in both metal solutions showed a tendency to decrease with the initial metal concentration (Fig.3).

Aluminum presented its highest removal efficiency at $50 \mathrm{mg} / \mathrm{L}(95 \%)$, and this property decreased slightly to values of $88-89 \%$ for initial metal concentrations of 100 and $150 \mathrm{mg} / \mathrm{L}$, suggesting that in this metal concentration range, binding sites present in the char surface were not saturated when the adsorbent dose was $2 \mathrm{~g} / \mathrm{L}$.

The removal efficiency for chromium was more sensitive to the initial metal concentration, varying from $79 \%$, at an initial concentration of $50 \mathrm{mg} / \mathrm{L}$ to $44 \%$ at 150 $\mathrm{mg} / \mathrm{L}$.

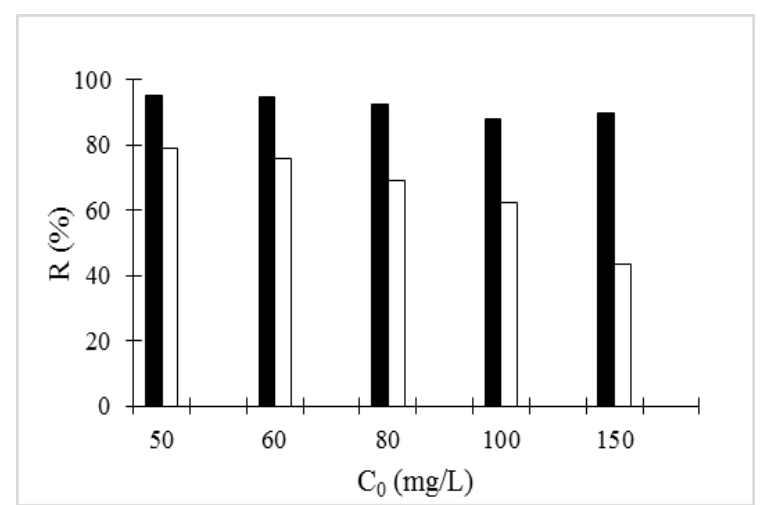

Fig.3. Effect of initial metal concentration, $\mathrm{C}_{0},(\mathrm{mg} / \mathrm{L})$ on the removal efficiency $\mathrm{R}(\%)$ of $\mathrm{Al}$ and $\mathrm{Cr}$.

Effect of contact time. The results for the adsorption capacities as a function of contact time are depicted in Fig.4.

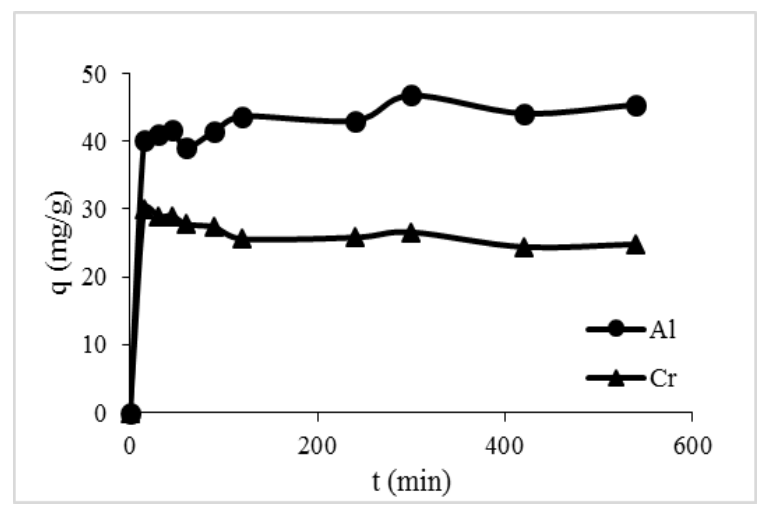

Fig. 4. Effect of contact time on adsorption capacities of $\mathrm{Al}$ and $\mathrm{Cr}$.

RDF char showed a sharp increase in the adsorption capacity during the first 15 minutes of adsorption (for both metals) and remained almost constant for higher 
contact times, reinforcing the idea that the adsorption mechanisms are dominated by electrostatic and hydrophobic interactions with the external surface of the char.

\section{Conclusions and Further Work}

The torrefaction process can contribute to upgrade RDF materials yielding a RDF char that is more homogeneous, hydrophobic and dense, with a higher stability and less land use requirements if stored in landfills. This char presents high ash content and reduced HHV so it could be more efficiently used in material applications than for energy recovery purposes. The RDF char presented good adsorption characteristics for $\mathrm{Al}$ and $\mathrm{Cr}$ in aqueous solutions, reaching removal efficiencies above $90 \%$ for aluminum and above $70 \%$ for chromium.

These results highlight the potential use of RDF char in industrial effluent remediation and future work includes tests with other RDF chars to evaluate the influence of initial RDF composition, tests with other heavy metals and other organic and inorganic contaminants, both in model systems and in real industrial effluents.

Industrial implementation of these technologies will require the adoption of cyber physical approaches to monitoring and control in view of the dimension of the material flows to be converted and because the heterogeneity of the materials requires automated adjustment of process operational conditions.

\section{References}

1. Krüger, B., Mrotzek, A., Wirtz, S.: Separation of harmful impurities from refuse derived fuels (RDF) by fluidized bed. Waste Manag. 34, 390--401 (2014)

2. Portuguese Diary of the Republic: Ministry Council Resolution $n^{\mathrm{o}} 11-\mathrm{C} / 2015.1^{\text {st }}$ series, 52 (March 16 $6^{\text {th } 2015)}$

3. Chen, W., Kuo, P.: A study on torrefaction of various biomass materials and its impact on lignocellulosic structure simulated by thermogravimetry. Energy. 35, 2580--2586 (2014)

4. Fu, F., Wang, Q.: Removal of heavy metal ions from wastewaters: A review. J. Environ. Manage. 92, 407--418 (2011)

5. Salam, O.E.A., Reiad, N.A., ElShafei, M.M.: A study of the removal characteristics of heavy metals from wastewater by low cost-adsorbents. J. Adv. Res. 2, 297--303 (2011)

6. Sheng, C., Azevedo, J.L.T.: Estimating the higher heating value of biomass fuels from basic analysis data. Biomass Bioenerg. 28, 499--507 (2005)

7. Pehlivan, E., Kahraman, H.: Sorption equilibrium of Cr (VI) ions on oak wood charcoal (Carbo Ligni) and charcoal ash as low-cost adsorbents. Fuel Process. Technol. 92, 65--70 (2011)

8. Choksi, P.M., Joshi, V.Y.: Adsorption kinetic study for the removal of nickel (II) and aluminum (III) from an aqueous solution by natural adsorbents. Desalination. 208, 216--231 (2007)

9. Deveci, H., Kar, Y.: Adsorption of hexavalent chromium from aqueous solutions by biochars obtained during biomass pyrolysis. J. Ind. Eng. Chem. 19, 190--196 (2013)

10. Kılıç, M., Kırbıyık, Ç., Çepelioğullar, O., Pütün, A.E.: Adsorption of heavy metal ions from aqueous solutions by bio-char, a by-product of pyrolysis. Appl. Surf. Sci. 283, 856-$862(2013)$ 